\title{
2,4-Dichlorophenoxy Acetic Acid as an Antidiabetic Drug: In silico, Preformulation and in vivo Approaches
}

\author{
Tamer Mohamed Shehata ${ }^{1,2, *}$, Mohammed Abdou Khedr ${ }^{1,3}$, Maged Elsayed Mohamed ${ }^{1,4}$ \\ ${ }^{1}$ College of Clinical Pharmacy, King Faisal University, Al-Ahsa, KINGDOM OF SAUDI ARABIA. \\ ${ }^{2}$ Department of Pharmaceutics and Industrial Pharmacy, Faculty of Pharmacy, University of Zagazig, Zagazig, EGYPT. \\ ${ }^{3}$ Department of Pharmaceutical Chemistry, Faculty of Pharmacy, Helwan University, Ein Helwan, Cairo, EGYPT. \\ ${ }^{4}$ Department of Pharmacognosy, Faculty of Pharmacy, University of Zagazig, Zagazig, EGYPT.
}

\begin{abstract}
Background: 2,4-Dichlorophenoxy acetic acid (2,4-D) was recently rediscovered as new anti-inflammatory agent through an in silico molecular modeling and in vivo anti-inflammatory inspection. Further computational investigations showed very close similarity between 2,4-D and pioglitazone in the mode of binding to PPAR $\gamma$ ligand binding pocket, suggesting an antidiabetic activity. Aim: To evaluate the binding strength of 2,4-D to PPAR $\gamma$ binding pocket and to improve the low water solubility of 2,4-D in formulation. Methods: particle size reduction via Nano Spray Dryer B-90 was chosen as possible technique to enhance the drug solubility and in turn facilitating its formulation. Chemical and physical properties of both raw and micronized forms of 2,4-D were investigated utilizing FTIR and DSC respectively. Additionally, dissolution profiles in different dissolution media were evaluated. Finally, the antidiabetic activity of micronized 2,4-D was investigated using streptozotocin (STZ)-induced animal model. Results: Revealed enhanced dissolution profiles for the micronized form of the drug on all media under investigation compared to its raw form. The in vivo antidiabetic activity for micronized 2,4-D form indicated no significant difference in its blood sugar lowering activity compared to pioglitazone as reference drug. Conclusion: the previous results could suggest micronized $2,4-D$ as a cheap antidiabetic agent with similar activity to pioglitazone.
\end{abstract}

Key words: 2,4-D, Micronized, Pioglitazone, Repositioning, Streptozotocin.

\section{INTRODUCTION}

In silico, repositioning has been widely used in the last few years to find new and best target for old drugs or chemicals. ${ }^{1,2}$ This approach requires the application of some computational techniques for the validation of the target selection. Many successful stories have been reported for the repositioning of some compounds and were introduced in a novel dosage form to treat potential diseases.

Peroxisome Proliferator Activated Receptor gamma (PPAR $\gamma$ ) agonists constitute a wellknown class of drugs for treatment of diabetes mellitus type II. ${ }^{3}$ Many modulators were reported to bind and activate these receptors such as thiazolidinedione. ${ }^{4}$ Recently, non-Steroidal Anti-Inflammatory Drugs (NSAIDs) such as Ibuprofen, Flurbiprofen and Indomethacin have been reported to bind and strongly activate PPAR $\gamma .^{5-8}$ Their binding was proven to be at the ligand-binding site of PPAR $\gamma$ where thiazolidinediones normally bind. This resulted in the raising of the possibility of new pharmacological actions to these agents.

2,4-dichloro phenoxy acetic acid (2,4-D) is one of the most commonly used phenoxy herbicides due to is efficacy and cheap cost. ${ }^{9}$ The wide use of that herbicide made it one of the most scru-
Submission Date: 09-11-2019; Revision Date: 08-01-2020; Accepted Date: 14-04-2020

DOI: 10.5530/ijper.54.2s.64 Correspondence: Dr. Tamer M Shehata ${ }^{1,2}$ 'Department of Pharmaceutical Sciences, College of Clinical Pharmacy, King Faisal University, Al-Ahsa-31982, KSA. 2Department of Pharmaceutics and Industrial Pharmacy, Faculty of Pharmacy, University of Zagazig-44519, Zagazig, EGYPT.

Phone: +966 564787190

E-mail: tshehata@kfu.edu.sa

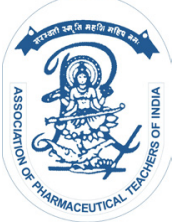

www.ijper.org 
tinized herbicides regarding its effect on human. Although some reports indicated possible health hazards associated with use of the herbicide, including carcinogenic activities, the majority of studies revealed its safety. ${ }^{10}$ Our research group has recently discovered 2,4-D as a new potential anti-inflammatory agent; which is strongly related to NSAID. ${ }^{11}$ 2,4-D was firstly reported by WHO in 1984 to produce hypoglycemic effect on humans when it was used to wipe up weeds. Additional investigation was performed by Mikov and coworker, ${ }^{12}$ showed hypoglycemic effect in Albino BALB/C mice following 2,4-D IP administration. However, no further work was done on such molecule to investigate its antidiabetic versus neither its hypoglycemic activity nor its suitable and effective dosage form.

Orally administered dosage forms represent the easiest way of drug delivery systems, since it is characterized by accuracy, stability and easy production. ${ }^{13}$ However, more than $40 \%$ of newly discovered active pharmaceutical ingredients (APIs) are poorly soluble in water and, according to biopharmaceutical classification system; could be categorized in class II or IV. ${ }^{14}$ Unfortunately, 2,4-D could be added to such categories of constituents showing poor aqueous solubility. 2,4-D showed water solubility of less than $0.9 \mathrm{mg} / \mathrm{mL}$, which could represent a major obstacle for its oral formulation and administration. Hence, enhancement of solubility and dissolution character of 2,4-D represented important goal in order to achieve higher drug absorption and bioavailability. Several enhancement approaches were developed to overcome solubility and dissolution difficulties such as particle size reduction, solubilization, salt formation, inclusion complex, solid dispersion and nano-suspension. ${ }^{15-17}$ Particle size reduction represents the traditional method for solubility and dissolution enhancement. Decreasing the particle size of poorly soluble drug resulted in increasing its surface area hence; improve its dissolution properties allowing its oral administration. ${ }^{18}$ Jet milling, ball milling, highpressure homogenization are considered as mechanical techniques practically used for particle size reduction. ${ }^{18,19}$ Micronization, can be defined as decreasing drug particle size less than 10 micrometer. ${ }^{18}$ Recently, Buchi pharmaceuticals introduced the Nano Spray Dryer B-90, through which powder micronization approach became accessible. ${ }^{20}$ Straightforward preparation and higher collection efficiency are achieved through their patented piezoelectically vibrating nozel in addition to electrostatic particle collector. ${ }^{21}$ Recently, Nano Spray Dryer B-90 is investigated intensively for solubility and dissolution enhancement of several APIs ${ }^{20,22,23}$
To the author's knowledge, the antidiabetic effect of pure 2,4-D following its oral administration had not been previously investigated. Accordingly, the main aim of the current study is the investigation of the antidiabetic activity of 2,4-D depending on its binding to PPAR $\gamma$ in silico. The in vivo antidiabetic effect of the drug was inspected after improving its solubility and dissolution characters through micronization technology.

\section{MATERIALS AND METHODS}

\section{Materials}

Molecular Operating Environment (MOE) 2013.08 package. $^{24}$ Absolute ethanol, glycerol, streptozotocin, pioglitazone and 2.4-D were purchased from SigmaAldrich.

\section{Molecular Docking Studies \\ Preparation of the Protein}

The crystal structure of PPAR $\gamma$ in complex with pioglitazone was downloaded from protein data bank (pdb code $=2 \mathrm{XKW})^{25}$ that was resolved by $\mathrm{x}$-ray diffraction method (resolution $2.02 \AA$ ) and R-value free 0.22. All coordinates of the binding site were derived from protein data bank where the ligand-binding domain was identified. The protein has to identical chains $\mathrm{A}$ and $\mathrm{B}$ as a result we deleted Chain B and used only Chain A. Also, polyethylene glycol molecule that was co-crystalized with chain A was deleted to simplify the docking process.

The crystal structure of PPAR $\gamma$ in complex with indomethacin was downloaded from protein data bank (pdb code $=4 \mathrm{XUM})$ to obtain the best binding pose for indomethacin.

\section{Molecular Docking Studies with MOE 2013.08.}

The chemical structures of the studied drugs was sketched by MOE 2013 builder. London dG was used as the scoring method while, affinity was used as second rescoring, the placement method was selected to be "Triangle matcher".

\section{Validation of the docking process.}

Validatin of the docking process was used by redocking the compounds using Leadit 2.1.5 ${ }^{26}$ software was purchased from BioSolveIT GmbH, Germany.

\section{Pharmaceutical Preformulation of 2,4-D.}

Pulverization and Size Adjustment of Raw 2,4-D.

Raw 2,4-D was pulverized using traditional porcelain mortar, followed by particle size adjustment through 
sieving method (U.S. standard test sieve ASTM E-11 specification, Fisher Scientific Company, USA).

\section{Preparation of Micronized Crystal using Buchi Spray Dryer B-90}

$100 \mathrm{mg} / \mathrm{mL}$ clear solution of 2,4-D in absolute ethanol was prepared. The previous solution was pumped into Nano Spray Dryer B-90 through pump 1 with flow rate $(7 \mathrm{~mL} / \mathrm{min})$. The drying gas was heated up to $68^{\circ} \mathrm{C}$ inlet temperature and $23^{\circ} \mathrm{C}$ out temperature. The spray mesh was $(7 \mu)$ and the nozzle was heated to $70^{\circ} \mathrm{C}$ with pressure $51 \mathrm{mbar}$. The drying gas flow rate was $85 \mathrm{ml} / \mathrm{min}$ and it was filtered before existing from the sprayer. The product was collected using a rubber special spatula. Microcrystal yield was calculated based on the original amount of raw drug utilized. $\%$ yield $=($ Weight of collected microcrystal $/$ Weight of raw drug) x 100

\section{Microscopical Examination and Particle Size Analysis}

Small amounts of raw and micronized 2-4 D were spread on a glass slide as a thin layer and examined for drug crystals using a inverted microscope with magnification power of $40 \mathrm{x}$. Photomicrographs were taken using a Olympus digital camera. One mg of either raw or micronized 2,4-D was suspended in $5 \mathrm{~mL}$ of $50 \%$ $\mathrm{v} / \mathrm{v}$ glycerol in water and used to assess their particle size. The measurement was carried out through Zetasizer (Malvern Instruments Inc., Westborough, MA).

\section{Angle of Repose}

Funnel method was used for angle of repose determination. Briefly, two grams either raw 2,4-D or its microcrystal form are allowed to flow through the funnel. The tip of the funnel was adjusted where it just touches the apex of powder's heap. The powder heap's diameter was measured and the angle of repose was calculated according to the following equation; $\tan \theta=\mathrm{h} / \mathrm{r}$, where $\mathrm{h}$ represents the height of the powder's heap and $r$ represents heap's diameter.

\section{Physical and Chemical Investigations Differential Scanning Calorimetry (DSC)}

The DSC thermograms were recorded (DSCShimadzu- 50, Japan). Samples (3 mg) were heated in hermetically sealed aluminum pans over the temperature of $50-200^{\circ} \mathrm{C}$ at a constant rate of $10^{\circ} \mathrm{C} / \mathrm{min}$ under a nitrogen purge $(30 \mathrm{~mL} / \mathrm{min})$ as stated in. ${ }^{27}$

\section{Fourier Transform Infrared (FTIR)}

FTIR spectra were obtained on a Perkin- Elmer (Perkin-Elmer- FTIR spectrophotometer, 1600 series,
Perkin-Elmer Corporation, Norwalk, USA) using $\mathrm{KBr}$ disk method. The scanning range was $200-4000 \mathrm{~cm}^{-1}$ and the resolution was $1 \mathrm{~cm}^{-1.27}$

\section{Solubility Determination}

Saturation solubility was measured, where, excessive powder of either raw 2,4-D or its microcrystal were added to $10 \mathrm{~mL}$ stoppered flask, followed by adding either distilled water, $0.1 \mathrm{~N} \mathrm{HCl}$ buffer, phosphate buffer $\mathrm{pH} 5.5$, phosphate buffer $\mathrm{pH} 6.8$ and phosphate buffer $\mathrm{pH}$ 7.4. The prepared suspensions were placed at $37 \pm 0.5^{\circ} \mathrm{C}$ and with shaking at $50 \mathrm{~min}^{-1}$ using GFL 1086 thermostatic shaker water bath (Labortechink, Burgwedel, Germany). After $24 \mathrm{hr}$, suspensions were filtered, diluted with the same dissolution medium and assayed spectrophotometrically at $282 \mathrm{~nm}$. Each experiment was carried out in triplicate.

\section{Drug Dissolution}

The dissolution of either raw 2,4-D or its microcrystal form was carried out according to the USP-24 rotating paddle method (dissolution tester, Erweka-DT-Frankfurt, Germany). Distilled water, $0.1 \mathrm{~N} \mathrm{HCl}$ buffer, phosphate buffer $\mathrm{pH}$ 5.5, phosphate buffer $\mathrm{pH} 6.8$ and phosphate buffer $\mathrm{pH} 7.4(500 \mathrm{~mL})$ were used as different dissolution medium. The stirring rate was $50 \mathrm{rpm}$ and the temperature was maintained at $37 \pm 0.5^{\circ} \mathrm{C} .250 \mathrm{mg}$ of either raw 2,4-D or its microcrystal was placed on the surface of the dissolution medium. At specified time intervals, $3 \mathrm{~mL}$ aliquots were withdrawn, filtered, diluted with dissolution medium and assayed spectrophotometrically at $282 \mathrm{~nm}$. Each experiment was carried out in triplicate. ${ }^{28}$

\section{In vivo Antidiabetic Activity \\ Animals}

Male Wistar rats (200 \pm 10 g, 6-8 weeks) were used. Rats were obtained from the Animal Breeding Center, Faculty of Veterinary Medicine, Zagazig University, Egypt. The animals were housed with food and water and maintained in standard laboratory conditions, at temperature $25 \pm 1^{\circ} \mathrm{C}$ and relative humidity $55 \pm 5 \%$ with a 12-hr light/dark cycle.

\section{Ethical statement}

All animal experiments comply with the ARRIVE guidelines and were carried out in accordance with the National Institutes of Health guide for the care and use of Laboratory animals (NIH Publications No. 8023, revised 1978). All animal experimental procedures and protocols were approved by the Animal Research Ethics Committee at Zagazig University, Egypt (number 3082015) and they were performed in accordance with 
the Guidelines for the Ethical Conduct for Animals Handling in Research, Zagazig University (ECAHRZU), Egypt.

\section{Experimental Design}

Antidiabetic activity was evaluated utilizing type II diabetic rats. Animals were rendered diabetic by intraperitoneal injection of streptozotocin $(50 \mathrm{mg} / \mathrm{kg})$ freshly dissolved in $0.1 \mathrm{M}$ citrate buffer at $\mathrm{pH}$ 4.5. Confirmed diabetes induction occurred 14 days following streptozotocin injection. Rats with serum glucose level over $250 \mathrm{mg} / \mathrm{dL}$ were selected for further experiments. Rats were randomly divided into 3 groups with 6 animals in each. $20 \mathrm{mg} / \mathrm{kg}$ micronized 2,4-D and pioglitazone, were given orally to group 3 and 4 leaving group 2 as untreated. A group 1 was created to represent normal rat without STZ injection. Blood samples were collected from animal tail and assessed for blood glucose levels at specified time intervals after glucose challenge by using Accu-Chek ${ }^{\circledR}$ active laboratory equipment supplied with Accu-Chek ${ }^{\circledR}$ active strips Code 970 (Roche, Mannheim, Germany). ${ }^{29}$

\section{Statistics}

For comparison, a one way analysis of variance (ANOVA) followed by the Least Significant Difference (LSD) as a post-hoc test was applied, using SPSS program version 14. The difference was considered as significant when $P<0.05$.

\section{RESULTS AND DISCUSSION}

PPAR are members of nuclear receptor supergene family that are acting as key sensors or glucose and lipids homeostasis. They have three isoforms; $\alpha, \beta$ and $\gamma$. PPAR $\gamma$ has a main role in the glucose metabolism and are used as targets for some anti-inflammatory, antidiabetic drugs. The ligand binding pocket of PPAR $\gamma$ has a conserved $\alpha$-helical core that is composed of $12 \alpha$-helices and $4 \beta$-sheets. The $\alpha$-helix 12 covers the ligand binding pocket and contains the most conserved residues; His323, His449 and Tyr473. Thiazolinediones are well known PPAR $\gamma$ agonists that act by binding to the ligand binding pocket by strong interaction with Tyr473. ${ }^{25}$ The anti-inflammatory activity of 2,4-D recently discovered and its structure similarly to Ibuprofen, together with the lately detected strong binding of NSAID to the PPAR $\gamma$ active binding site ${ }^{25}$ in a mode similar to the thiazolidinedione class of antidiabetic drug. All the above reasons triggered the investigation of the antidiabetic activity of 2,4-D, both in silico and in vivo, which is the main purpose of this current study. The poor solubility of $2,4-\mathrm{D}$ in aqueous solution prompted its pharmaceutical formulation to a dosage form suitable for oral administration and thus facilitate the in vivo determination of its antidiabetic effect.

\section{Molecular Docking}

The binding mode of both indomethacin and pioglitazone were reported in protein bank (pdb 4XUM 2XKW respectively). The main interactions formed by indomethacin were; hydrophobic interactions with Phe363 through $\pi-\pi$ stacking with the p-chlorobenzoyl moiety, three hydrogen bonding with His449, Tyr473 and His323. At physiological $\mathrm{pH}$ the histidine amino acid can form a positive charge therefore, a possible salt bridge formation with the carboxylate anion of indomethacin can occur that can strengthen the interactions (Figure 1A). On the other hand, the interactions formed by pioglitazone were three hydrogen bonds with His323, Tyr473 and Cys285 (Figure 1B). The protein data bank used the deprotonated state for the carboxylate group of indomethacin (Figure 1A).

In order to evaluate the binding mode of 2,4-D and to compare it to different PPAR $\gamma$ agonists, the docking study was done for 2,4-D, indomethacin, ibuprofen, flurbiprofen and pioglitazone inside the PPAR $\gamma$ ligand binding site. According to the docking results, both indomethacin and 2,4-D showed two hydrogen bonds formed by the carboxylic group with both Cys285 and Ser289 (Figure 2).

On the other hand, the docking of pioglitazone was not able to accommodate it and keep its interactions and showed no interactions with the specified residues. In addition, pioglitazone bulky structure resulted in some clashes and some parts to exit from the binding site (Figure 2C).
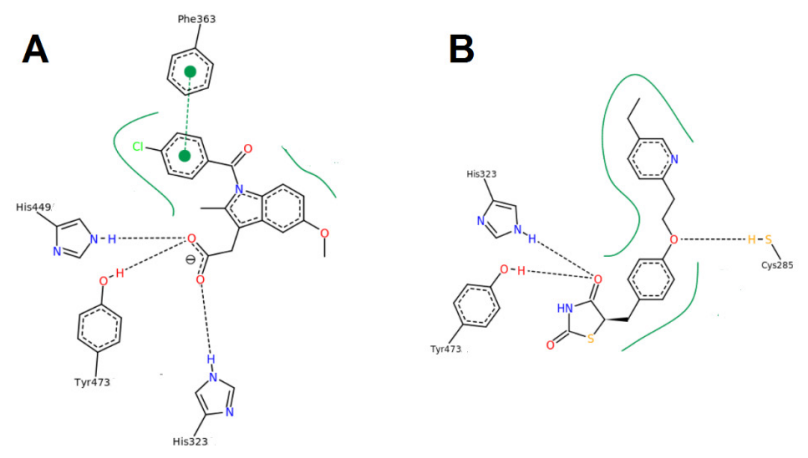

Figure 1: The main PPAR- $\gamma$ agonists interactions that were derived from protein data bank for both $A$. Indomethain showing its hydrogen bond with Cys285 B. Pioglitazone that illustrates three hydrogen bonds with Cys285, His323 and Tyr473. 

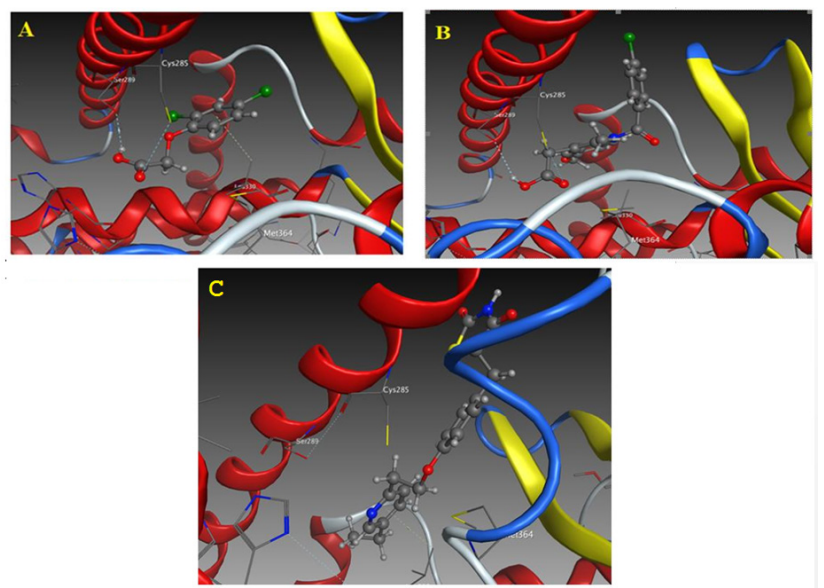

Figure 2: The best orientation mode of both 2,4-D (A) and indomethacin (B). It shows the interactions with both Cys285 and Ser289. (C) The docking of bulky structure of pioglitazone resulted in deviation from its original pose and affected the interactions.

The docking score of $2,4-\mathrm{D}$ was $-7.35 \mathrm{kcal} / \mathrm{mol}$ and for indomethacin was $-7.37 \mathrm{kcal} / \mathrm{mol}$ (Table 1). The docking results were of high prediction that 2,4-D has a good fitting and binding mode with less RMSD toward binding to PPAR $\gamma$ when compared to NSAIDs and thiazolidindione agent, accordingly, it was predicted to have antidiabetic activity. Nevertheless, to investigate the antidiabetic activities of 2,4-D, solubility and dissolution characters of the drug has to be improved through pharmaceutical formulations.

\section{Validation of the docking process}

In order to validate the docking, a second docking process was conducted using Leadit 2.5.1 program, the program that is widely used by protein data bank. The results showed that Indomethacin was the top ranked docking score $(-24.56 \mathrm{kcal} / \mathrm{mol})$, Ibuprofen and Fluoriprofen shared almost the same vlaue $(-23.15$ and -23.11 $\mathrm{kcal} / \mathrm{mol}$ respectively). 2,4-D showed $-22.85 \mathrm{kcal} / \mathrm{mol}$ while pioglitazone was the last score $-17.20 \mathrm{kkcal} / \mathrm{mol}$. This confirmed the results obtained by MOE 2013 docking (Table 1). Regarding the formed interactions, it was found that 2,4-D formed a number off interactions with the conserved residues like; His323, His449, Tyr473, Tyr327 and Ser289 when compared to the other ligands (Figure 3).

\section{Pharmaceutical Preformulation of 2,4-D}

Commercial 2,4-D powder was characterized by relatively large and non-homogenous particle size. Raw 2,4-D were well pulverized and particle size of the resulting raw crystalline powder were adjusted by sifting through standard sieve and and the pulverized powder

Table 1: Molecular docking results of 2,4-D, DAIDs and pioglitazone.

\begin{tabular}{|c|c|c|}
\hline & $\begin{array}{c}|c| \\
\text { Kcal/mol (MOE2013) }\end{array}$ & $\begin{array}{c}\text { Docking score with } \\
\text { lea it 2.5.1 Kcal/mol }\end{array}$ \\
\hline 2,4-D & -7.35 & -22.85 \\
\hline Pioglitazone & -6.85 & -17.20 \\
\hline Ibuprofen & -7.12 & -23.15 \\
\hline Fluriprofen & -6.94 & -23.11 \\
\hline Indometacin & -7.37 & -24.56 \\
\hline
\end{tabular}

A

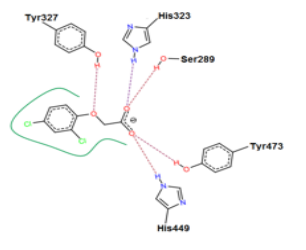

c

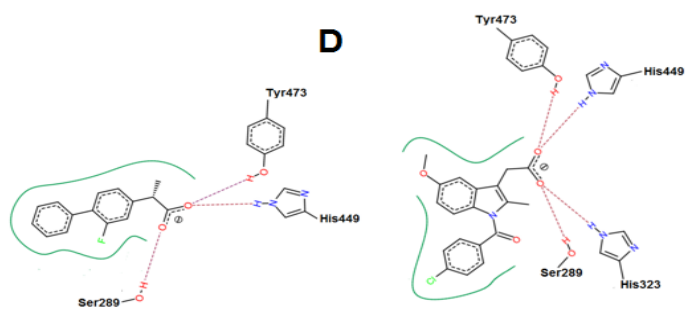

E

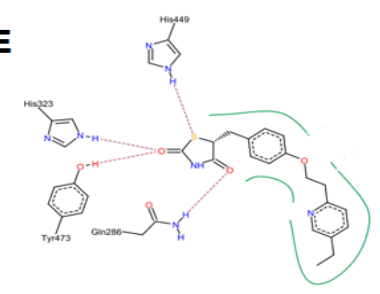

Figure 3: Molecular docking ith leadit 2.5.1 showing the best pose of: A)2,4-D, B) Ibuprofen, C) Fluoriprofen,

D) Indomethacin and E) Pioglitaone.

successfully passed through sieve No. $45(355 \mu)$ and retained on sieve No. $100(150 \mu)$.

In order to prepare the micronized form of 2,4-D, a solution of the drug in absolute ethanol were pumped into spray head of Buchi spray dryer B-90. Piezielectrically driven mesh vibrations in the spray head resulted in spying drug-ethanol droplets in a homogenous and micronized size. Hot drying gas feed into the equipment chamber resulted in sudden drying of the sprayed particles in addition to electrically charging the resulting dried micronized particles. Dried fine particles were adhered on the oppositely charged collector and then collected using a particle scraper. ${ }^{30}$

The percentage yield of particles was found to be $75 \pm 5 \%$. The loss of yield could be attributed to the particles that are sucked into the glass-drying chamber before 
reaching the collecting electrode, due to the smaller particle size and in turn smaller density. ${ }^{31}$

\section{Physical and chemical investigations}

In order to verify that enhancement of dissolution rate is not due to change the physico-chemical structure. DSC is a physical technique used to investigate the variation involved in phase change. In addition it is reflected the Crystallinity of the raw materials. ${ }^{32}$ DSC was performed and the results are shown in Figure 4.

The DSC thermograms, of both raw and micronized 2,4-D revealed a similar sharp endothermic peak at $141^{\circ} \mathrm{C}$ which is consistent with melting point of pure 2,4-D. There is no change in the melting point, indicating that the solid state of the particles did not exhibit any physical change in the crystalline structure of the raw drug following spray drying. FTIR results (Figure 5) indicated the presence of strong peak at $1725 \mathrm{~cm}^{-1}$ peak which can be attributed to the $\mathrm{C}=\mathrm{O}$ carbonyl band of carboxylic group. The peaks at 1600 and $1580 \mathrm{~cm}^{-1}$ are assigned to the aromatic ring. $\mathrm{CH}$ stretching vibration in the aromatic ring is a weak peak at $3040 \mathrm{~cm}^{-1}$. In addition, the peaks 2925 and $2854 \mathrm{~cm}^{-1}$ stretching arise from the asymmetric and symmetric stretching vibration peaks of $\mathrm{CH}_{2}$. The peaks at $1180 \mathrm{~cm}^{-1}$ and $1100 \mathrm{~cm}^{-1}$ are due to the $\mathrm{C}-\mathrm{O}$ vibration in $\mathrm{Ph}-\mathrm{O}-\mathrm{CH}_{2}-$. The $\mathrm{C}-\mathrm{C}$ vibration in $\mathrm{CH}_{2}-\mathrm{C}=\mathrm{O}$ appears at $1420 \mathrm{~cm}^{-1 .}$ Finally, the broad stretching band from $2500-3300 \mathrm{~cm}^{-1}$ is due to the $-\mathrm{OH}$ group. It is clear that the two FTIR spectra are almost the same, which means that the chemical structure of the drug has not been affected.

\section{Microscopic Examination, Particle Size Analysis and Angle of Repose}

Microscopic examination of the prepared raw and micronized 2,4-D indicated a crystal shaped powders with a marked optically recognized difference of their particle size (Figure 6). The particle size of raw 2,4-D was previously adjusted to be in range of $150-355 \mu$. On the other hand, the average particle size of micronized 2,4-D was $5.1 \mu \mathrm{m}$ measured with PDI 0.299. In order to evaluate enhancement of powder flowability, the angle of repose was measured and the results were $35.5^{\circ} \mathrm{C}$ (passable flow) and $26.4^{\circ} \mathrm{C}$ (good flow) for raw and micronized 2,4-D respectively, indicating free flowing powder, ${ }^{33}$ which is a key requirement for a good pharmaceutical formulation and further processing of microcrystal 2,4-D could be straightforward.

\section{Solubility Determination}

Saturation solubility or thermodynamic solubility can be defined as the solubility of compound in

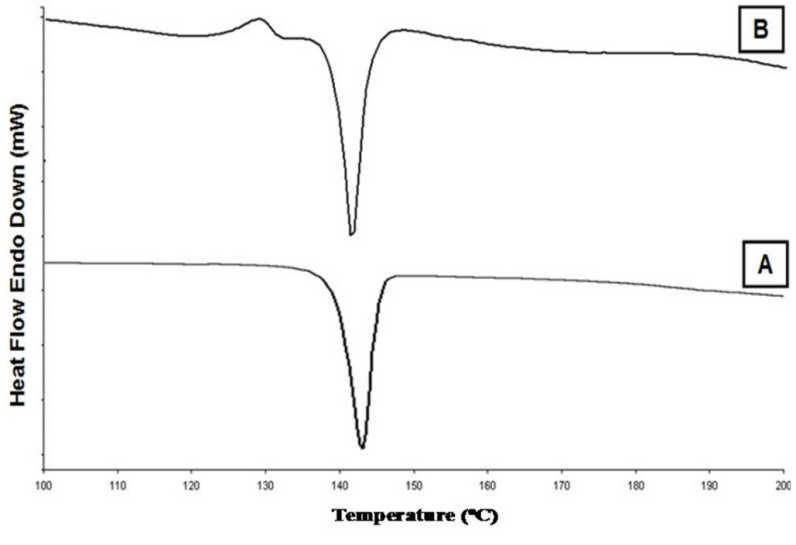

Figure 4: DSC spectra of 2,4-D; A. Raw crystalline form; B. Microcrystalline form.

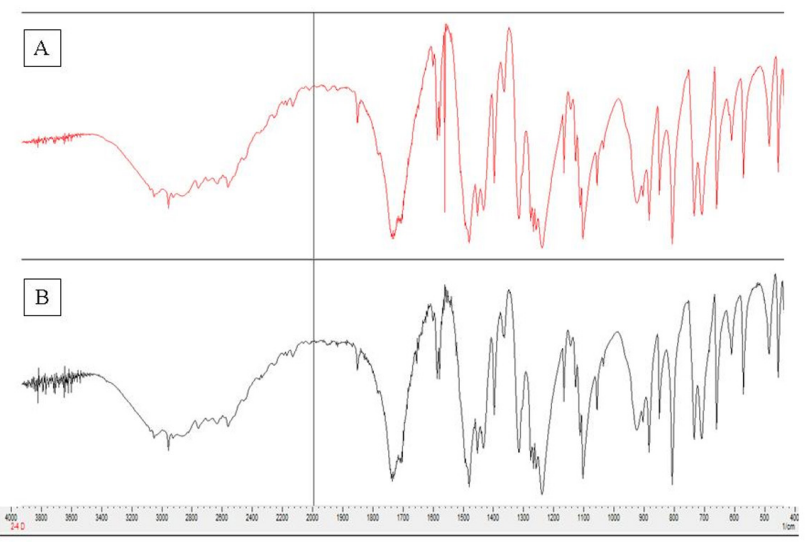

Figure 5: FTIR spectra of 2,4-D; A. Raw crystalline form; B. Microcrystalline form.
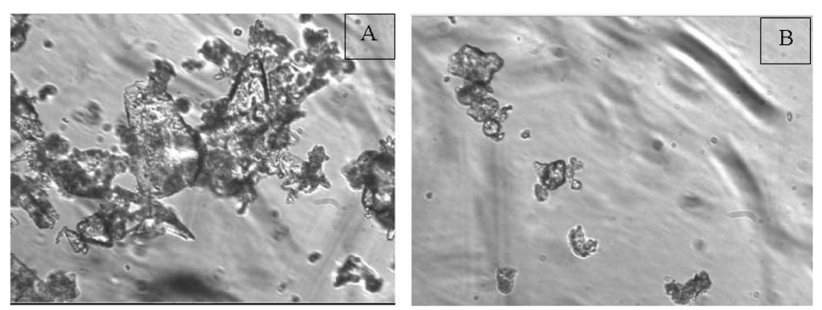

Figure 6: Optical Photomicrographs of 2,4-D A. Raw crystalline form; B. Microcrystalline form (magnification power is $40 \mathrm{X}$ ).

equilibrium with excess undissolved materials at the end of the dissolution process. ${ }^{14}$ Several factors are affecting the saturation solubility of the compound including: polymorphism, particle size, particle shape, buffer $\mathrm{pH}$ and common ion effect. Saturation solubility represents a gold standard for product development, therefore, the solubility of raw and micronized 2,4-D was assessed and the results are shown in Table 2.

From the results obtained, it is clear that a significant enhancement in the water solubility of micronized 


\begin{tabular}{|c|c|c|}
\hline Media & $\begin{array}{c}\text { Crystalline 2,4-D } \\
(\mathrm{mg} / \mathrm{mL}) \pm \mathrm{SD}\end{array}$ & $\begin{array}{l}\text { Microcrystalline 2,4-D } \\
(\mathrm{mg} / \mathrm{mL}) \pm \mathrm{SD}\end{array}$ \\
\hline $\begin{array}{l}\text { Dist. } \\
\text { Water }\end{array}$ & $0.84 \pm 0.07$ & $1.59 \pm 0.06$ \\
\hline pH 1.2 & $0.36 \pm 0.05$ & $0.48 \pm 0.01$ \\
\hline $\mathrm{pH} 5.5$ & $1.73 \pm 0.11$ & $1.99 \pm 0.05$ \\
\hline $\mathrm{pH} 6.8$ & $13.79 \pm 0.23$ & $15.83 \pm 0.16$ \\
\hline pH7.4 & $22.63 \pm 0.25$ & $26.99 \pm 0.19$ \\
\hline
\end{tabular}

2,4-D $1.596 \pm 0.012 \mathrm{mg} / \mathrm{mL}$ in comparison with 0.846 $\pm 0.014 \mathrm{mg} / \mathrm{mL}$ for raw drug. The improvement of drug solubility could be attributed to the marked reduction on the particle size as a result of the spray-drying process. On the other hand, as shown in Table 2. The solubility of micronized $2,4-\mathrm{D}$ was $0.483 \pm 0.011,1.894$ $\pm 0.051,15.830 \pm 0.161$ and $24.993 \pm 0.191 \mathrm{mg} / \mathrm{mL}$ for $\mathrm{pH}$ 1.2, buffer $\mathrm{pH} 5.5$, buffer $\mathrm{pH} 6.8$ and buffer $\mathrm{pH}$ 7.4 respectively. The solubility of raw 2,4-D was 0.3623 $\pm 0.009,1.736 \pm 0.107,13.790 \pm 0.226$ and $22.635 \pm$ $0.088 \mathrm{mg} / \mathrm{mL}$ for $\mathrm{pH} 1.2$, buffer $\mathrm{pH} 5.5$, buffer $\mathrm{pH}$ 6.8 and buffer $\mathrm{pH} 7.4$ respectively. The solubility of the both raw and micronized 2,4-D can be arranged ascendingly in respect to the increase in medium $\mathrm{pH}$. The lesser solubility of both raw 2,4-D and its micronized form in $\mathrm{pH} 1.2$ represent an obstacle for drug dissolution following oral administration, which may result in reducing their bioavailability. ${ }^{34}$ Fortunately, micronized 2,4-D showed about 25\% increased solubility in $\mathrm{pH} 1.2$ along with significant increase in other media under investigation.

\section{Drug Dissolution}

The rate of drug dissolution is a limiting step in the absorption process following oral drug administration. Figure 7. Represents the dissolution process of either raw 2,4-D or its microcrystal in distilled water, $0.1 \mathrm{~N}$ $\mathrm{HCl}$ buffer, buffer $\mathrm{pH} 5.5$, buffer $\mathrm{pH} 6.8$ and buffer $\mathrm{pH}$ 7.4. Interestingly, the data obtained showed that, within $120 \mathrm{~min}$ the dissolution in distilled water was $54 \%$ and $98 \%$ for raw and micronized 2,4-D respectively. Additionally, within $120 \mathrm{~min}$ the dissolution in $0.1 \mathrm{~N}$ $\mathrm{HCl}$ buffer was $49 \%$ and $73 \%$ for raw and micronized 2,4-D respectively. A significant dissolution rate enhancement was obtained for micronized 2,4-D in both distilled water and $0.1 \mathrm{~N} \mathrm{HCl}$ buffer, The previous enhancements are of great importance during drug formulation in addition to increasing drug absorption following oral administration. ${ }^{35}$ Moreover, $100 \%$
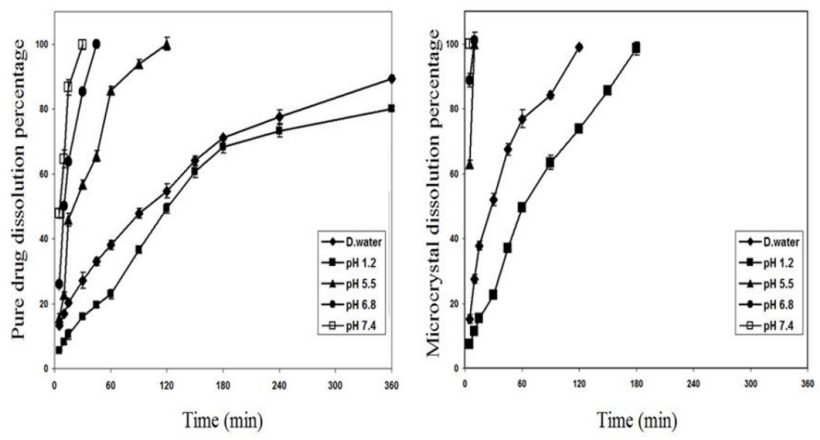

Figure 7: In vitro dissolution profiles of 2,4-D. A: Raw crystalline form; B: Microcrystalline form in different media at $37^{\circ} \mathrm{C}$. Data represented as mean $\pm \operatorname{SD}(n=3)$.

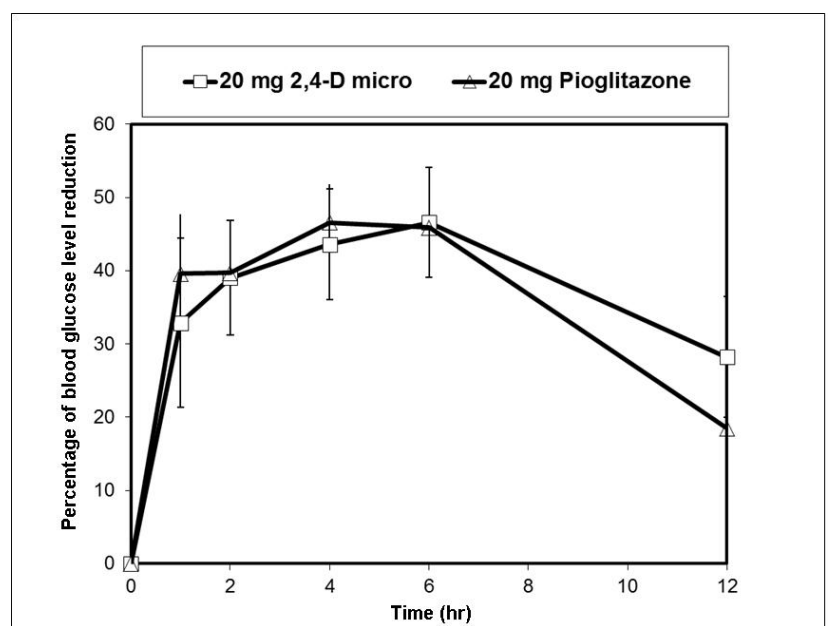

Figure 8: Blood glucose reduction level time profile following administration of $20 \mathrm{mg}$ of either 2,4-D raw drug, 2,4-D micronized and pioglitazone orally into diabetic induced Wistar rats.

dissolution was obtained within $15 \mathrm{~min}$ and $120 \mathrm{~min}$ for of micronized and raw 2,4-D respectively.

\section{In vivo Antidiabetic Activity}

The antidiabetic activity of $20 \mathrm{mg}$ of micronized 2,4-D was evaluated on STZ induced diabetic adult male Wistar rats. Pioglitazone was used as a positive control. The blood glucose level against time profile following oral administration of $20 \mathrm{mg}$ of micronized 2,4-D or pioglitazone is shown in Figure 8.

A significant reduction in blood glucose level was obtained in all groups under investigation $(p<0.05)$. In addition, no significant difference in the blood glucose level was obtained among micronized 2,4-D-treated group and pioglitazone-treated group.

\section{CONCLUSION}

2,4-Dichlorophenoxy acetic acid was proven computationally to have good binding activity to PPAR $\gamma$, 
which suggested its antidiabetic activity. The molecular modeling and docking studies showed very close similarity between 2,4-D and pioglitazone in mode of binding to PPAR $\gamma$ and its similarity to NSAIDs in affinity toward PPAR $\gamma$. The drug water solubility was enhanced through micronization techniques. Following oral administered into rats with induced diabetes, micronized 2,4-D showed significant reduction of the blood glucose level. Having the advantages of being cheap, low toxicity and easily chemically synthesized drug, 2,4-D could attract high attention as a potentially new anti-diabetic agent.

\section{ACKNOWLEDGEMENT}

The authors acknowledge all the effort exerted by Mr. Tamim Alyahian in preparations, assistance and support in the experimental part of this study.

\section{Funding}

This research was funded by Deanship of Scientific Research, King Faisal University, Nasher track, Grant number (186148).

\section{CONFLICT OF INTEREST}

The authors declare no conflict of interest.

\section{ABBREVIATIONS}

2,4-D: 2,4-Dichlorophenoxy acetic acid; PPAR $\gamma$ : Peroxisome Proliferator Activated Receptor gamma; FTIR: Fourier Transform Infrared; DSC: Differential Scanning Calorimetry; STZ: Streptozotocin; NSAIDs: Non-Steroidal Anti-Inflammatory Drugs; APIs: Active pharmaceutical ingredients; MOE: Molecular Operating Environment.

\section{REFERENCES}

1. Khedr MA, Massarotti A, Mohamed ME. Rational Discovery of (+) (S) Abscisic Acid as a Potential Antifungal Agent: A Repurposing Approach. Scientific Reports. 2018;8(1):8565.

2. Sakr TM, Khedr MA, Rashed HM, et al. In silico-Based Repositioning of Phosphinothricin as a Novel Technetium-99m Imaging Probe with Potential Anti-Cancer Activity. Molecules. 2018;23(2):496.

3. Kim HI, Ahn YH. Role of Peroxisome Proliferator-Activated Receptor-y in the Glucose-Sensing Apparatus of Liver and $\beta$-Cells. Diabetes. 2004;53(suppl 1): S60-5.

4. Puhl AC, Bernardes A, Silveira RL, et al. Mode of peroxisome proliferatoractivated receptor gamma activation by luteolin. Mol Pharmacol. 2012;81(6):788-99.

5. Bernardo A, Minghetti L. PPAR-gamma agonists as regulators of microglial activation and brain inflammation. Curr Pharm Des. 2006;12(1):93-109.

6. Bernardo A, Minghetti L. Regulation of Glial Cell Functions by PPAR-gamma Natural and Synthetic Agonists. PPAR Res. 2008;2008:864140.
7. Zhao X, Quigley JE, Yuan J, et al. PPAR-alpha activator fenofibrate increases renal CYP-derived eicosanoid synthesis and improves endothelial dilator function in obese Zucker rats. Am J Physiol Heart Circ Physiol. 2006;290(6):H2187-95.

8. Lehmann JM, Lenhard JM, Oliver BB, et al. Peroxisome proliferator-activated receptors alpha and gamma are activated by indomethacin and other non-steroidal anti-inflammatory drugs. J Biol Chem. 1997;272(6):3406-10.

9. Islam F, Wang J, Farooq MA, et al. Potential impact of the herbicide 2,4-dichlorophenoxyacetic acid on human and ecosystems. Environment International. 2017; 111:332-51.

10. Garabrant DH, Philbert MA. Review of 2,4-dichlorophenoxyacetic acid (2,4-D) epidemiology and toxicology. Crit Rev Toxicol. 2002;32(4):233-57.

11. Khedr MA, Shehata TM, Mohamed ME. Repositioning of 2,4-Dichlorophenoxy acetic acid as a potential anti-inflammatory agent: In silico and Pharmaceutical Formulation study. European Journal of Pharmaceutical Sciences. 2014;65(Supplement C):130-8.

12. Mikov I, Vasović V, Mikov A, et al. Hypoglycemic Effect of Herbicide 2,4-Dichlorophenoxyacetic Acid (2,4-D). Pestic Phytomed. 2010;25(4):349-52.

13. Jeffries MD, Gannon TW, Brosnan JT, et al. Factors Influencing Dislodgeable 2, 4-D Plant Residues from Hybrid Bermudagrass (Cynodon dactylon L. x C. transvaalensis) Athletic Fields. Plos One. 2016;11(2):e0148992.

14. Savjani KT, Gajjar AK, Savjani JK. Drug Solubility: Importance and Enhancement Techniques. ISRN Pharmaceutics. 2012;2012:10.

15. Dizaj SM, Vazifehasl Z, Salatin S, et al. Nanosizing of drugs: Effect on dissolution rate. Res Pharm Sci. 2015;10(2):95-108.

16. Raval MK, Patel JM, Parikh RK, et al. Dissolution enhancement of chlorzoxazone using cogrinding technique. International Journal of Pharmaceutical Investigation. 2015;5(4):247-58.

17. Ullah M, Ullah H, Murtaza $\mathrm{G}$, et al. Evaluation of Influence of Various Polymers on Dissolution and Phase Behavior of CarbamazepineSuccinic Acid Cocrystal in Matrix Tablets. Bio Med Research International. 2015;2015:870656.

18. Khadka P, Ro J, Kim H, et al. Pharmaceutical particle technologies: An approach to improve drug solubility, dissolution and bioavailability. Asian Journal of Pharmaceutical Sciences. 2014;9(6):304-16.

19. Salazar J, Muller RH, Moschwitzer JP. Combinative Particle Size Reduction Technologies for the Production of Drug Nanocrystals. Journal of Pharmaceutics. 2014;2014:14.

20. Harsha SN, Aldhubiab BE, Nair AB, et al. Nanoparticle formulation by Büchi B-90 Nano Spray Dryer for oral mucoadhesion. Drug Design, Development and Therapy. 2015;9:273-82.

21. Harsha S. Pharmaceutical suspension containing both immediate/sustainedrelease amoxicillin-loaded gelatin nanoparticles: Preparation and in vitro characterization. Drug Design, Development and Therapy. 2013;7:1027-33.

22. Baba K, Nishida K. Steroid Nanocrystals Prepared Using the Nano Spray Dryer B-90. Pharmaceutics. 2013;5(1):107-14

23. Baba K, Nishida K. Calpain inhibitor nanocrystals prepared using Nano Spray Dryer B-90. Nanoscale Research Letters. 2012;7(1):436.

24. Molecular Operating Environment (moe). 2013.08 ed. 1010 Sherbooke St. West, Suite \#910, Montreal, QC, Canada, H3A 2R7: Chemical Computing Group Inc. 2014.

25. Puhl AC, Milton FA, Cvoro A, et al. Mechanisms of peroxisome proliferator activated receptor $\mathrm{Y}$ regulation by non-steroidal anti-inflammatory drugs. Nuclear Receptor Signaling. 2015;13(1):e004-e.

26. Lead IT version 2.5.1; BioSolvelT GmbH, Sankt Augustin, Germany.

27. Khedr AA, Shehata TM, El-ghamry HA. Formulation, in vitro Optimization and in vivo Evaluation of Sustained Release Transdermal Patches of Venlafaxine Hydrochloride. Latin American Journal of Pharmacy. 2017;36(8):1664-74.

28. Shehata TM, Abdallah MH, Ibrahim MM. Proniosomal oral tablets for controlled delivery and enhanced pharmacokinetic properties of acemetacin. AAPS Pharm Sci Tech. 2015;16(2):375-83.

29. Arokiyaraj S, Balamurugan R, Augustian P. Antihyperglycemic effect of Hypericum perforatum ethyl acetate extract on streptozotocin-induced diabetic rats. Asian Pacific Journal of Tropical Biomedicine. 2011;1(5):386-90.

30. Shehata TM, Ibrahima MM. BÜCHI nano spray dryer B-90: a promising technology for the production of metformin hydrochloride-loaded alginate- 
gelatin nanoparticles. Drug Development and Industrial Pharmacy. 2019;45(12):1907-14.

31. Li X, Anton N, Arpagaus C, et al. Nanoparticles by spray drying using innovative new technology: the Buchi nano spray dryer B-90. J Control Release. 2010;147(2):304-10.

32. Yang TM, Su CS, Li JS, et al. Recrystallization and Micronization of p-Toluenesulfonamide Using the Rapid Expansion of Supercritical Solution (RESS) Process. Crystals. 2019;9(9):449.
33. Shah RB, Tawakkul MA, Khan MA. Comparative Evaluation of Flow for Pharmaceutical Powders and Granules. AAPS Pharm Sci Tech. 2008;9(1):250-8.

34. Raghuvanshi S, Pathak K. Recent Advances in Delivery Systems and Therapeutics of Cinnarizine: A Poorly Water Soluble Drug with Absorption Window in Stomach. Journal of Drug Delivery. 2014;2014:479246.

35. Jain S, Patel N, Lin S. Solubility and dissolution enhancement strategies: Current understanding and recent trends. Drug Dev Ind Pharm. 2015;41(6):875-87.

\section{PICTORIAL ABSTRACT}

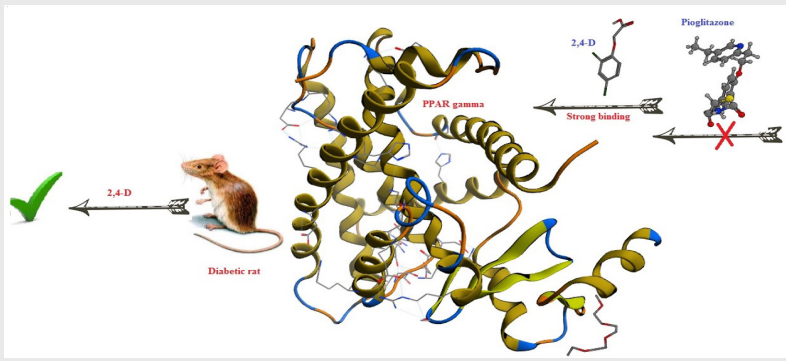

\section{About Authors}

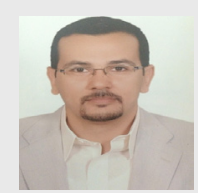

Dr. Tamer M. Shehata, is currently an Associate Professor of Pharmaceutics and Industrial Pharmacy, College of Clinical Pharmacy, King Faisal University, KSA and Faculty of Pharmacy, Zagazig University, Egypt. Dr. Shehata, obtained his Ph.D in 2009 from Faculty of Pharmacy, Okayama University, Japan. Dr. Shehata is interested in drug delivery systems, drug targeting, pharmacokinetics and nanoparticles. He published several articles in highly reputed scientific journals and he is reviewer in many journals.

\section{SUMMARY}

- 2,4-Dichlorophenoxy acetic acid was proven computationally to have good binding activity to PPAR $\gamma$, which suggested its antidiabetic activity.

- The molecular modeling and docking studies showed very close similarity between 2,4-D and pioglitazone in mode of binding to PPAR $\gamma$ and its similarity to NSAIDs in affinity toward PPAR $\gamma$.

- The drug water solubility was enhanced through micronization techniques.

- Following oral administered into rats with induced diabetes, micronized 2,4-D showed significant reduction of the blood glucose level.

- Having the advantages of being cheap, low toxicity and easily chemically synthesized drug, 2,4-D could attract high attention as a potentially new anti-diabetic agent.

Cite this article: Shehata TM, Khedr MA, Mohameda ME. 2,4-Dicholophenoxy Acetic Acid as an Antidiabetic Drug: In silico, Preformulation and in vivo Approaches. Indian J of Pharmaceutical Education and Research. 2020;54(2s):s79-s87. 